OPEN ACCESS

Edited by:

Shuanglin Qu,

Hunan University, China

Reviewed by:

Chunsen $\mathrm{Li}$

Fujian Institute of Research on the Structure of Matter (CAS), China

Hongjun Fan,

Dalian Institute of Chemical Physics

(CAS), China

${ }^{*}$ Correspondence:

Anan Wu

ananwu@xmu.edu.cn

Xin Lu

xinlu@xmu.edu.cn

Specialty section:

This article was submitted to

Theoretical and Computational

Chemistry,

a section of the journal

Frontiers in Chemistry

Received: 29 June 2019

Accepted: 20 August 2019

Published: 06 September 2019

Citation:

Sun Q, Hong P, Wei D, Wu A, Tan K and LUX (2019) Chemoselectivity in

Gold(l)-Catalyzed Propargyl Ester Reactions: Insights From DFT

Calculations. Front. Chem. 7:609.

doi: 10.3389/fchem.2019.00609

\section{Chemoselectivity in Gold(I)-Catalyzed Propargyl Ester Reactions: Insights From DFT Calculations}

\author{
Qing Sun, Pan Hong, Dongdong Wei, Anan Wu*, Kai Tan and Xin Lu* \\ State Key Laboratory of Physical Chemistry of Solid Surfaces, Fujian Provincial Key Laboratory for Theoretical and \\ Computational Chemistry, Department of Chemistry, College of Chemistry and Chemical Engineering, Xiamen University, \\ Xiamen, China
}

Au-catalyzed propargyl ester reactions have been investigated by a comprehensive density functional theory (DFT) study. Our calculations explain the experimental observed chemoselectivity of Au-catalyzed propargyl ester reactions very well by considering all possible pathways both in the absence and presence of 1,2,3-triazole (TA). The "X-factor" of TA is disclosed to have triple effects on this reaction. First of all, it can stabilize and prevent rapid decomposition of the Au catalyst. Secondly, the existence of TA promotes the nucleophilic attack and alters the chemoselectivity of this reaction. Moreover, TA acts as a "relay" to promote the proton transfer.

Keywords: homogeneous gold catalysis, chemoselectivity, alkynes, DFT, 1,2,3-triazole

\section{INTRODUCTION}

Homogeneous gold catalysis has been proven a powerful tool with its extensive applications in modern organic synthesis over the past decades (Hashmi and Hutchings, 2006; Gorin and Toste, 2007; Hashmi, 2007, 2010, 2014; Corma et al., 2011; Rudolph and Hashmi, 2012; Obradors and Echavarren, 2014a,b; Hopkinson et al., 2016). Of particular importance is the selective activation of alkynes, allenes, and alkenes by homogeneous gold catalysis to produce chemically interesting intermediates (Hashmi, 2003; Jiménez-Núñez and Echavarren, 2008; Abu Sohel and Liu, 2009; Krause and Winter, 2011; Ohno, 2013; Zhang, 2014; Dorel and Echavarren, 2015). It is currently accepted that the cationic gold(I) acts as a soft $\pi$-Lewis acid and the carbon-carbon multiple bond is activated via a complex of the alkynes/allenes/alkenes-coordinated $\mathrm{Au}^{+}$(Hashmi, 2003; Fürstner and Davies, 2007). The active catalysts employed in the activation of alkynes are generally in the form of $[\mathrm{L}-\mathrm{Au}]^{+}$(Fürstner and Davies, 2007; Hashmi, 2007; Shapiro and Toste, 2008). Various experiments have demonstrated that the ligands play a crucial role in the reactivity of the cationic gold catalysis (Gorin et al., 2008; Wang et al., 2012a; Ding et al., 2016; Ebule et al., 2016). Among the gold catalysts reported, the phosphine ligands $\left(\mathrm{PR}_{3}\right)$ have taken a prominent place. However, it surfers from the rapid decomposition, resulting in poor reactivity (Chen et al., 2010; Wang et al., 2012b). Recent developments in the N-heterocyclic carbene (NHC) derivatives have significantly expanded the scope of ligands by improving thermal and substrate stability in addition to good reactivity (de Frémont et al., 2005; Marion et al., 2006; Diez-Gonzalez and Nolan, 2008; Diez-Gonzalez et al., 2009; Ramón et al., 2010).

Interestingly, Shi et al. developed 1,2,3-triazole (TA)-bound gold complexes as an effective catalysts (denoted as TA-Au) toward the alkynes activation (Chen et al., 2008; Liu et al., 2008; Sengupta et al., 2008; Duan et al., 2009a,b; Yan et al., 2010). This class of Au-catalysts exhibited better performance along with much lower overall costs in catalyzing the transformations of various 
alkynes, in comparison with the expensive NHC-Au catalysts (Duan et al., 2009a; Chen et al., 2010; Wang et al., 2010, 2011a,b,c; Hosseyni et al., 2015). More fascinating is the TA-Au catalysts even led to unique chemoselectivity. For instance, it was found that the propargyl ester underwent Rautenstrauch rearrangement to produce cyclopentenones with use of a conventional gold catalyst $\mathrm{PPh}_{3} \mathrm{AuOTf}$ (Scheme 1A; Shi et al., 2005), but was hydrated to form $\alpha$-acetoxy ketone with use of a TA-Au catalyst (Scheme 1B; Wang et al., 2012b). The underlying mechanism of such unique effects of TA in gold catalysis remains unknown as an "X-factor" (Chen et al., 2010), and deserves further indepth exploration. Herein, we present our theoretical work on the mechanism of the aforementioned Au-catalyzed transformations of propargyl ester in the absence/presence of TA, aiming to the unique role of TA.

\section{COMPUTATIONAL DETAILS}

All calculations were carried out with the Gaussian 09 program (Frisch et al., 2013). The geometries of all the species were fully optimized by using the M06 functional (Zhao and Truhlar, 2008) with the ultrafine integration grid. The 6-31G(d,p) (Ditchfield et al., 1971; Hehre et al., 1972; Hariharan and Pople, 1973, 1974) basis set was employed for C, H, O, N, P, and the Stuttgart/Dresden small-core RECP (relativistic effective core potential) plus valence double-basis set (SDD) (Andrae et al., 1990) was applied for Au. This combination of functional and basis sets has been frequently used in the mechanistic investigations on Au-catalyzed organic transformations (Shu et al., 2015; Shen et al., 2017a,b). Frequency calculations at the same level were performed to confirm each stationary point to be either a local minimum or a transition state (TS). All transition states were verified by using the intrinsic reaction coordinate (IRC) (Gonzalez and Schlegel, 1990) calculations. Gibbs free energies were obtained with frequency calculations on the optimized structures in acetone at standard condition, given in unit of $\mathrm{kcal} / \mathrm{mol}$. The solvent effects of acetone $(\varepsilon=20.493)$ were taken in account by using the SMD-flavor (Marenich et al., 2009) of self-consistent reaction field (SCRF) theory. The atomic charges were analyzed by natural bond orbital (NBO) theory (Foster and Weinhold, 1980; Carpenter and Weinhold, 1988; Reed et al., 1988). All 3D structures were generated by the CYLview (Legault, 2009).

It should be mentioned that theoretical modeling of reactions in wet chemistry requires not only the use of the SCRFbased solvent-effect model but also the explicit involvement of several $\mathrm{H}_{2} \mathrm{O}$ molecules as close environment. For example, the explicit involvement of a water trimer cluster led to better results in the theoretical simulation of organometallic reactions (Kovács et al., 2005; Shi et al., 2007). Accordingly, we took similarly a water trimer cluster model to simulate the hydration reactions (Figures S1, S2). To save computational costs, the bulky triphenylphosphine $\left(\mathrm{PPh}_{3}\right)$ ligand used in experiments was simplified as trimethylphosphine $\left(\mathrm{PMe}_{3}\right)$ and such simplification was been validated by our current results (Scheme S1) and by previous theoretical work on Au-catalyzed reactions (Shi et al., 2007; Faza and López, 2013; Jin et al., 2016).

\section{RESULTS AND DISCUSSION}

Under wet condition, Au-catalyzed reactions of propargyl ester can undergo two types of skeleton rearrangement, i.e., 1,2acyloxy migration and 3,3-rearrangement (Path $\mathrm{A}$ and $\mathrm{D}$ in Scheme 2), and hydration (Path B, E, and G in Scheme 2). To understand the detailed reaction mechanisms at the molecular level, we considered all possible channels for the current model, as shown in Scheme 2 and Scheme S2.

Before starting to investigate the detailed reaction mechanisms, we first focused on the complexes of the alkyne-coordinated $\left[\mathrm{AuPMe}_{3}\right]^{+}$as it is well-accepted that Au-catalyzed activation of alkynes begins with the coordination of the cationic $\left[\mathrm{AuPMe}_{3}\right]^{+}$, to the substrate. Two types of complexes ( $\mathbf{A}_{\text {anti-PMe3 }}$ and $\left.\mathbf{A}_{\text {syn-PMe3 }}\right)$ were found under nearly equilibrium state, slightly favoring the $\mathbf{A}_{\text {anti-PMe3 }}$ over $\mathbf{A}_{\text {syn-PMe3 }}(0.0$ vs. $0.4 \mathrm{kcal} / \mathrm{mol}$, Figure 1). Thus, we took $\mathbf{A}_{\text {anti-PMe3 }}$ as the reference, with respect to which the relative free energies were given throughout the whole work, unless otherwise noted.

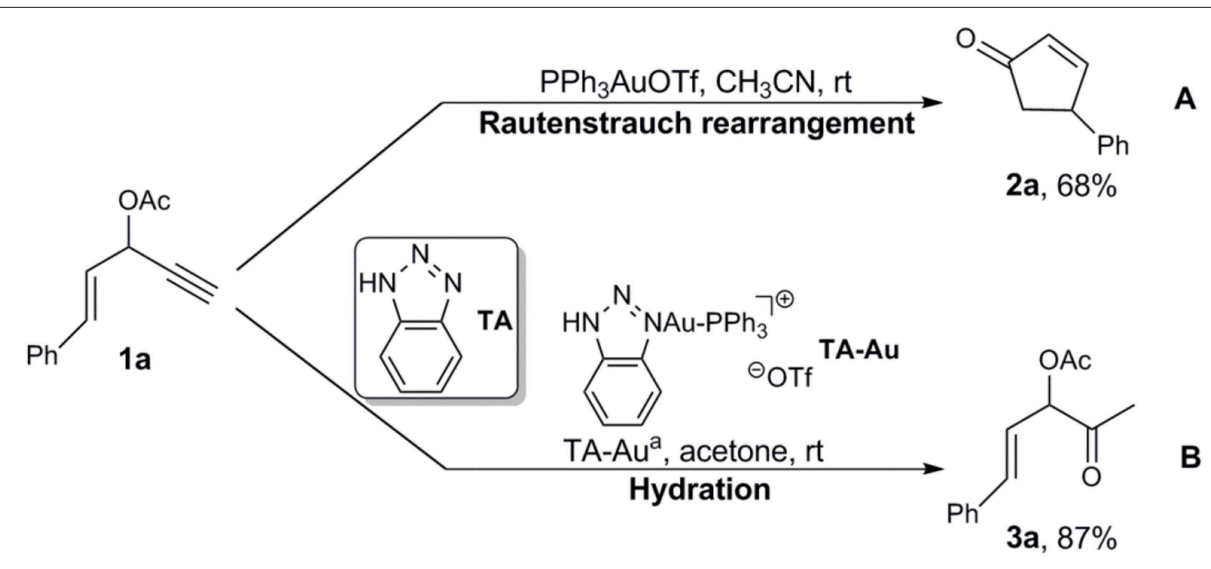

SCHEME 1 | Au-catalyzed propargyl ester reactions reported by (A) Toste and (B) Shi groups. 


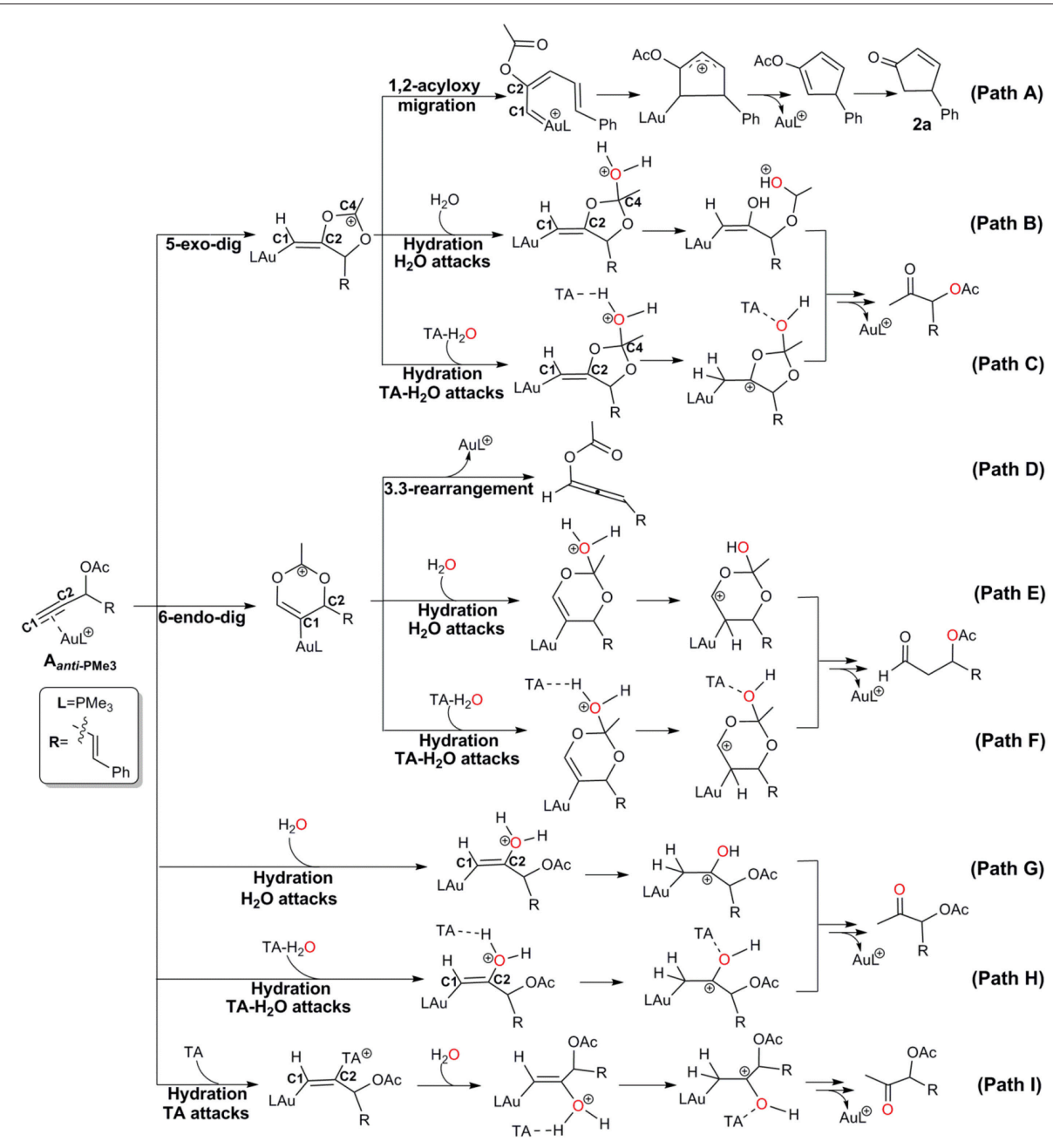

SCHEME 2 | Schematic possible pathways for the Au-catalyzed propargyl ester reactions.

\section{Chemoselectivity of Au-Catalyzed Propargyl Ester Reactions in the Absence of TA}

In the absence of TA, acetonitrile, although it is an excellent ligand, can be easily substituted by the alkynes to form the alkynecoordinated $\left[\mathrm{AuPMe}_{3}\right]^{+}$for further reactivities. The substrate exchange process is endergonic by $2.0 \mathrm{kcal} / \mathrm{mol}$ (Figure 2).

The Rautenstrauch rearrangement, namely the formation of cyclopentenone $\mathbf{2 a}$, is initialized with a 1,2-acyloxy migration as illustrated in Scheme 2 (Path A) and the corresponding energy profile is shown in Figure 2. A nucleophilic attack of the lone pair on the carboxyl oxygen to the $\mathbf{C} 2$ site in $\mathbf{A}_{\text {anti-PMe3 }}$ via a 5exo-dig cyclization, leading to the formation of a five-membered vinyl-gold intermediate $\mathbf{B}$. This transformation only requires an activation free energy of $7.7 \mathrm{kcal} / \mathrm{mol}$ and is thermodynamically neutral process (exergonic by only $0.9 \mathrm{kcal} / \mathrm{mol}$ ). C1 and C2 atoms in the five-membered vinyl-gold intermediate $\mathbf{B}$ change to $s p^{2}$ hybridization, rendering that the formal positive charge partially distributes on $\mathbf{C 4}$ atom (0.97e, Figure S3). The lone pair on the acetate group can also attack the $\mathbf{C} 1$ site in $\mathbf{A}_{\text {anti-PMe} 3 \text {, }}$

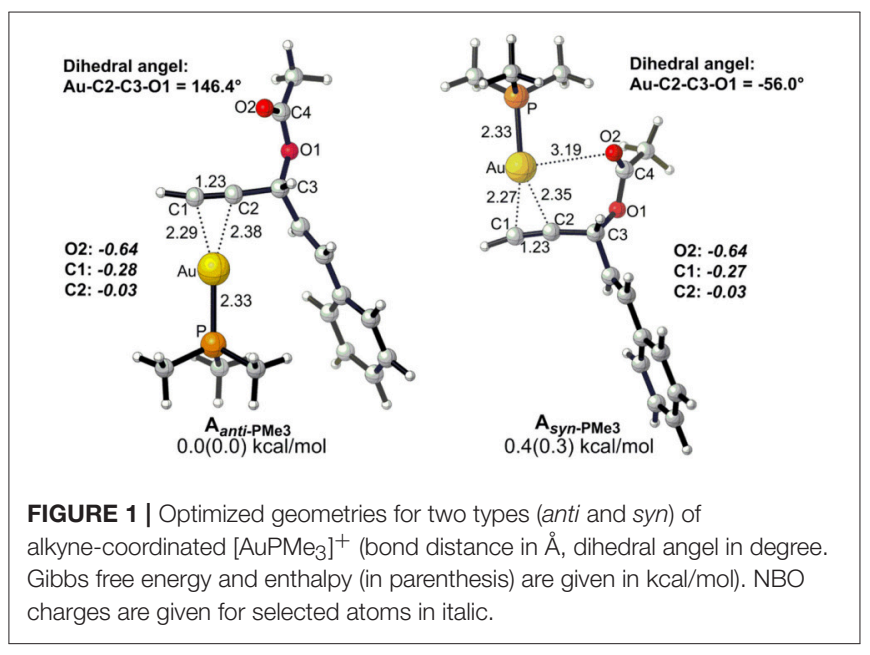

leading to a 3,3-rearrangement via a 6-endo-dig cyclization (Path $\mathrm{D}$ in Scheme 2). However, our calculations indicate that the 6endo-dig cyclization process is kinetically unfavorable and its 


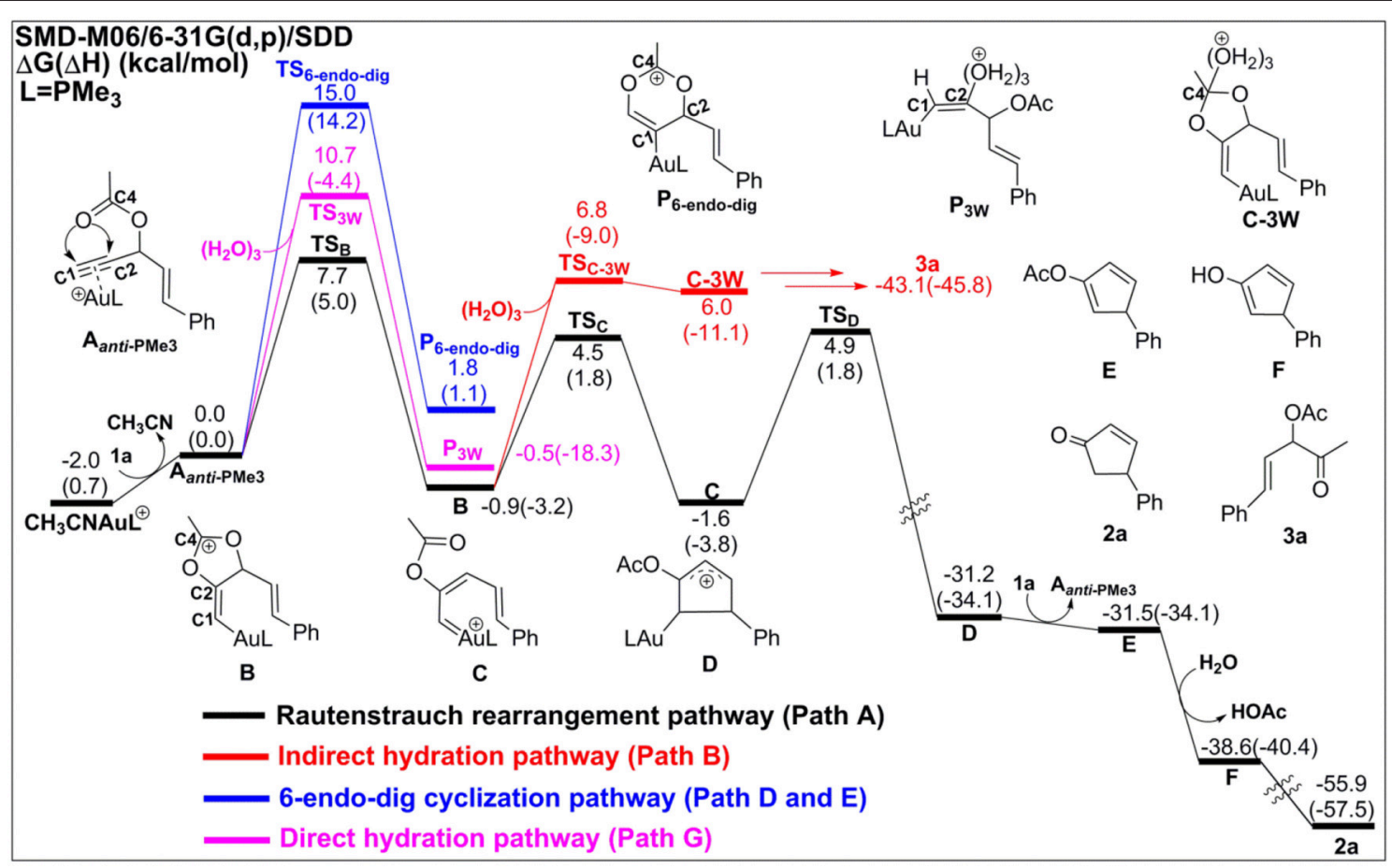

FIGURE 2 | Relative Gibbs free energy and enthalpy (in parenthesis) (kcal/mol) profiles for Au-catalyzed Rautenstrauch rearrangement (black line), hydration reactions

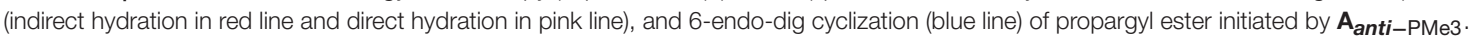

apparent activation free energy is $7.3 \mathrm{kcal} / \mathrm{mol}$ higher than that for the 5-exo-dig cyclization (Figure 2). Thus, the subsequent 3,3-rearrangement and hydration reactions (Path $\mathrm{D}$ and $\mathrm{E}$ in Scheme 2) are not considered in current work. This significantly higher activation barrier $(15.0 \mathrm{kcal} / \mathrm{mol})$ via the 6 -endo-dig cyclization, in comparison with that $(7.7 \mathrm{kcal} / \mathrm{mol})$ for the 5 -exodig cyclization, is in line with its nucleophilic nature as the NBO charge analysis indicates that $\mathbf{C} 2(-0.03 \mathrm{e})$ bears less charges than C1 (-0.28e) (Figure 1).

Note that $\mathrm{C} 3-\mathrm{O} 1$ bond in intermediate $\mathbf{B}$ is significantly weaker than that of normal $\mathrm{C}-\mathrm{O}$ single bond $(1.43 \AA)$ and other $\mathrm{C}-\mathrm{O}$ bonds in intermediate $\mathrm{B}$ (1.46 for C2-O2, 1.28 for C4-O1, and $1.28 \AA$ for C4-O2, Figure S3), as demonstrated by its elongated bond length of $1.50 \AA$. Hence, the 1,2-acyloxy migration can easily take place via a cleavage of the $\mathrm{C} 3-\mathrm{O} 1$ bond, resulting to the isomerization into the vinyl gold-carbenoid $\mathbf{C}$ with a free energy release of $0.7 \mathrm{kcal} / \mathrm{mol}$. The activation free energy is calculated to be $5.4 \mathrm{kcal} / \mathrm{mol}$. Cyclization of $\mathbf{C}$ followed by the elimination of gold catalysts gives the cyclopentadiene $\mathbf{E}$ and final hydrolysis furnishes the desired cyclopentenone 2a. The whole process proceeds smoothly with a low apparent activation free energy of $9.7 \mathrm{kcal} / \mathrm{mol}$, and is highly exothermic with a free energy release of $53.9 \mathrm{kcal} / \mathrm{mol}$, as shown in Figure 2.

The hydration reactions can be initiated by nucleophilic attack of water cluster at either carbocation $\mathrm{C} 4$ via the favored 5-exo-dig cyclization (Path B in Scheme 2) or directly to C2 in $\mathbf{A}_{\text {anti-PMe3 }}$ (Path G in Scheme 2). Due to the nature of its nucleophilic attack, the water cluster is more inclined to attack the positively charged C4 (0.97e) (denoted as indirect hydration) instead of the negative charged $\mathbf{C 2}(-0.03 \mathrm{e})$ (denoted as direct hydration). The calculated free energy barriers are 7.7 and $10.8 \mathrm{kcal} / \mathrm{mol}$, respectively (Figure 2). Further proton transfer and elimination of gold catalyst for both processes lead to the same ketone. In comparison to the Rautenstrauch rearrangement, the hydration reactions are clearly both kinetically and thermodynamically unfavorable, as shown in Figure 2. Thus, according to our calculations, Au catalyst selectively produces cyclopentenones in the absence of TA. In this sense, our calculations provide a theoretical support for experimental observations and insights into the chemoselectivity of Au-catalyzed propargyl ester reactions in the absence of TA.

\section{Chemoselectivity of Au-Catalyzed Propargyl Ester Reactions in the Presence of TA}

Experiments have demonstrated that TA provides unique chemoselectivity in addition to improved thermal and substrate stability (Chen et al., 2010; Wang et al., 2010, 2011a,b,c, 2012c). According to our calculations, TA can indeed stabilize the $\mathrm{Au}$ catalysts by coordinating with the cationic $\mathrm{Au}$ in $\left[\mathrm{AuPMe}_{3}\right]^{+}$with a stabilization free energy of $19.0 \mathrm{kcal} / \mathrm{mol}$ (Scheme S1). However, the longer Au-N bond (2.13 $\AA$ vs. $2.10 \AA$, Figure S4) in comparison to that in the anionic TA coordinated Au complex implies that the neutral TA can dissociate and release the coordination site for substrate activation. Under 
the experimental conditions, the substrate exchange process is calculated to be endergonic by $6.3 \mathrm{kcal} / \mathrm{mol}$, leading to the alkyne-coordinated $\left[\mathrm{AuPMe}_{3}\right]^{+}$(Scheme S1). Subsequent Rautenstrauch rearrangement (Path A in Scheme 2) and 3,3rearrangement (Path D in Scheme 2) are the same as that catalyzed by the $\left[\mathrm{AuPMe}_{3}\right]^{+}$in the absence of TA. Herein, we will focus on the hydration pathways (Path $\mathrm{C}, \mathrm{F}, \mathrm{H}$ and I in Scheme 2) of TA-Au-catalyzed propargyl ester reactions. Path F is excluded due to the high activation free energy for the 6-endodig cyclization as mentioned above, and the hydration pathway initialized by a direct attack of TA to C2 (Path I) is also ruled out because of its high activation free energy of $12.3 \mathrm{kcal} / \mathrm{mol}$.

As an electron-rich moiety, TA can be used not only as a ligand to the cationic $\mathrm{Au}$ but also as a good hydrogen bond acceptor. It can readily form a hydrogen-bond complex TA- $\left(\mathrm{H}_{2} \mathrm{O}\right)_{3}$ with water cluster although this process is endergonic by $3.2 \mathrm{kcal} / \mathrm{mol}$. A significantly increased dipole in TA- $\left(\mathrm{H}_{2} \mathrm{O}\right)_{3}$ cluster [7.0 vs. 1.7 Debye in $\left(\mathrm{H}_{2} \mathrm{O}\right)_{3}$, Figure S4] may offer a facile route for the nucleophilic attack with the assistant of TA.

Similar as those in the absence of TA, the hydration reactions can be initiated by the nucleophilic attack of TA- $\left(\mathrm{H}_{2} \mathrm{O}\right)_{3}$ cluster at either the carbocation $\mathbf{C 4}$ via the favored 5-exo-dig cyclization (Path C in Scheme 2) or directly to $\mathbf{C 2}$ in $\mathbf{A}_{\text {anti-PMe3 }}$ (Path H in Scheme 2). Path C is found to be the most favorable pathway for the TA-Au-catalyzed hydration reactions. Herein, we only focus on the process of Path $\mathrm{C}$ in detail. To clarify the whole mechanism and the role of TA, we divided the hydration into three processes: TA-assisted nucleophilic addition of water, proton transfer, and the formation of $\alpha$-acetoxy ketone, as shown in Scheme 3.

\section{Process 1: TA-Assisted Nucleophilic Addition of Water}

As discussed above, the water cluster is more inclined to attack the positively charged $\mathbf{C 4}(0.97 \mathrm{e})$ instead of the negative charged C2 $(-0.03 \mathrm{e})$ due to the nature of nucleophilic attack. For the TA$\left(\mathrm{H}_{2} \mathrm{O}\right)_{3}$ cluster, the same will occur. A complex B-3W-TA can be located on the potential energy surface with a stabilization energy of $0.9 \mathrm{kcal} / \mathrm{mol}$, as shown in Figure 3. It is interesting to note that the TA- $\left(\mathrm{H}_{2} \mathrm{O}\right)_{3}$ cluster itself is unstable with respect to the separated TA and $\left(\mathrm{H}_{2} \mathrm{O}\right)_{3}$ by $3.2 \mathrm{kcal} / \mathrm{mol}$. However, the complex B-3W-TA is more stable than $\mathbf{B}-\mathbf{3 W}$ in the absence of TA by $5.1 \mathrm{kcal} / \mathrm{mol}$. This is mainly due to the enhanced electrostatic interaction caused by TA, as indicated by the increased charge transfer $(0.13 \mathrm{e})$ (Figure S3) between TA- $\left(\mathrm{H}_{2} \mathrm{O}\right)_{3}$ and the fivemembered vinyl-gold intermediate $\mathbf{B}$ moiety. On the other hand, the shortened distance between Ow1 and C4 (2.37 in B-3WTA vs. $2.50 \AA$ in B-3W) also prove this (Figure S3). As a consequence, TA-assisted water addition requires a small free energy barrier of $3.0 \mathrm{kcal} / \mathrm{mol}$, which is $4.7 \mathrm{kcal} / \mathrm{mol}$ lower than that in the absence of TA, leading to the intermediate C-3W-TA. In all, with the assistance of TA, it is more efficient for the water addition in this nucleophilic attack process.

\section{Process 2: Proton Transfer to the Terminal Carbon}

After the formation of intermediate C-3W-TA, it would be likely to undergo the protodeauration via proton-transfer, initialized by proton transfer to the terminal carbon (C1). A two-step pathway is located for this process as shown in Figure 4. A nearly barrierless $(0.3 \mathrm{kcal} / \mathrm{mol})$ double proton-transfer firstly takes place starting from C-3W-TA. That is, the proton Hw2 from the nucleophilic attacking Ow1 transfers to Ow2 and simultaneously the proton $\mathbf{H w} 3$ on Ow2 transfers to $\mathrm{N} 1$ atom of TA, resulting to the intermediate D-3W-TA (Figure S5). This process is exergonic by $5.0 \mathrm{kcal} / \mathrm{mol}$, which is in line with the fact that TA is a good hydrogen bond acceptor. The second step is the proton transfer from $\mathbf{H}_{\mathrm{N}}$ on the TA to the terminal carbon $\mathbf{C 1}$. Note that this proton transfer step needs to overcome a barrier of 5.4 $\mathrm{kcal} / \mathrm{mol}$ to form the intermediate E-3W-TA with a free energy release of $17.4 \mathrm{kcal} / \mathrm{mol}$. Based on our computational results, we can draw conclusions that TA can stabilize the proton and act as a "relay" to accept and donate a proton. Similar mechanism has

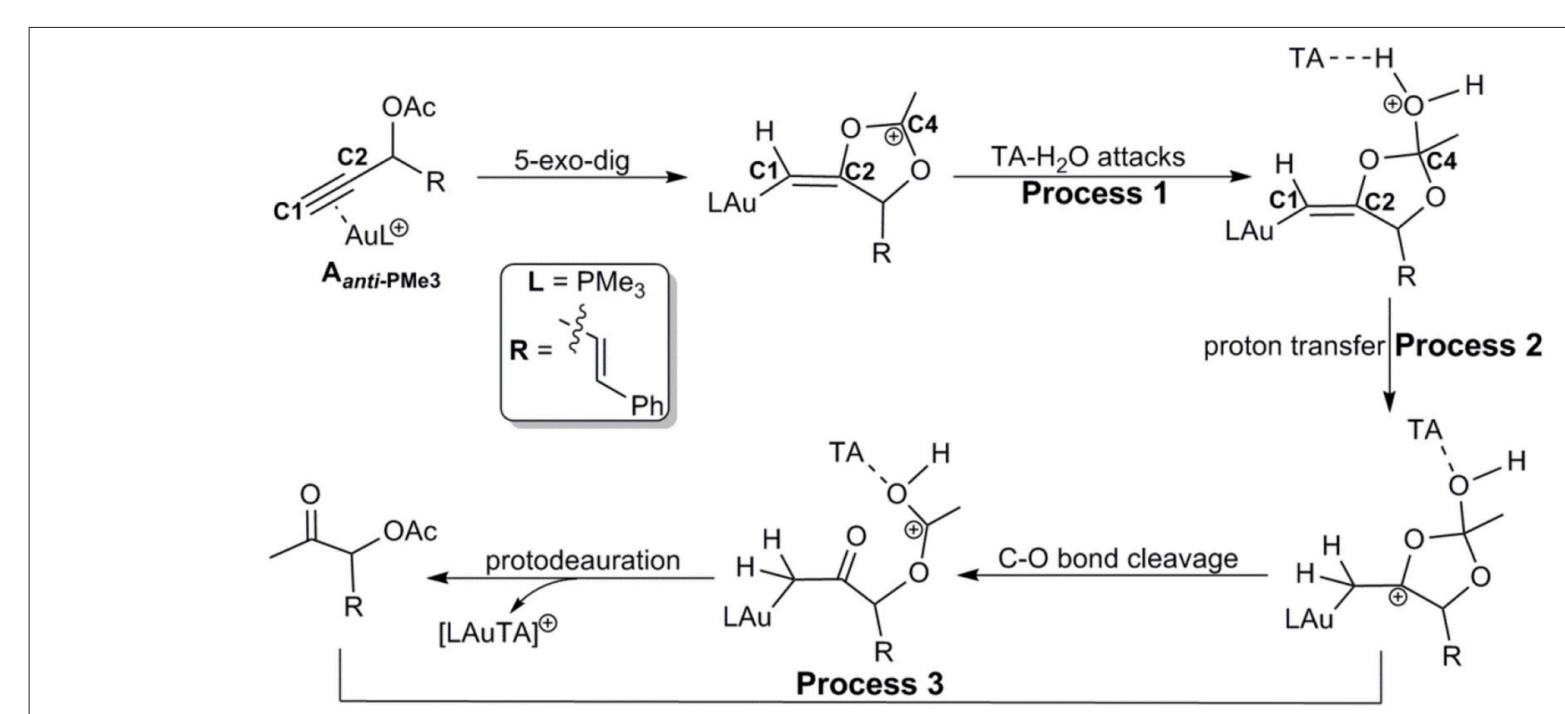

SCHEME 3 | Path C for the TA-Au-catalyzed hydration of propargyl ester. 


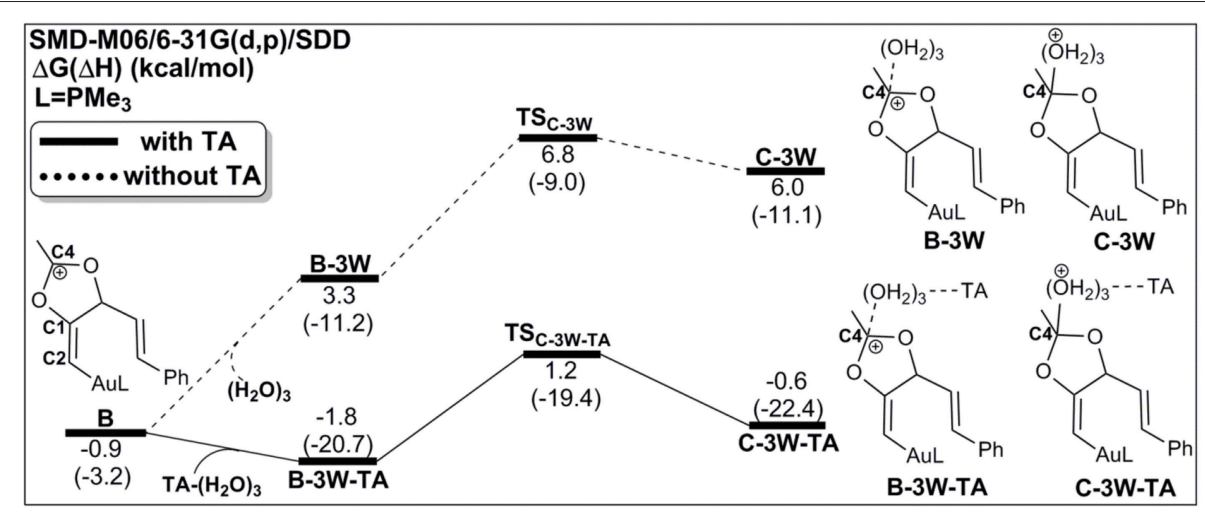

FIGURE 3 | Relative Gibbs free energy and enthalpy (in parenthesis) (kcal/mol) profiles for the nucleophilic addition of water in the absence/presence of TA (dashed/solid line).

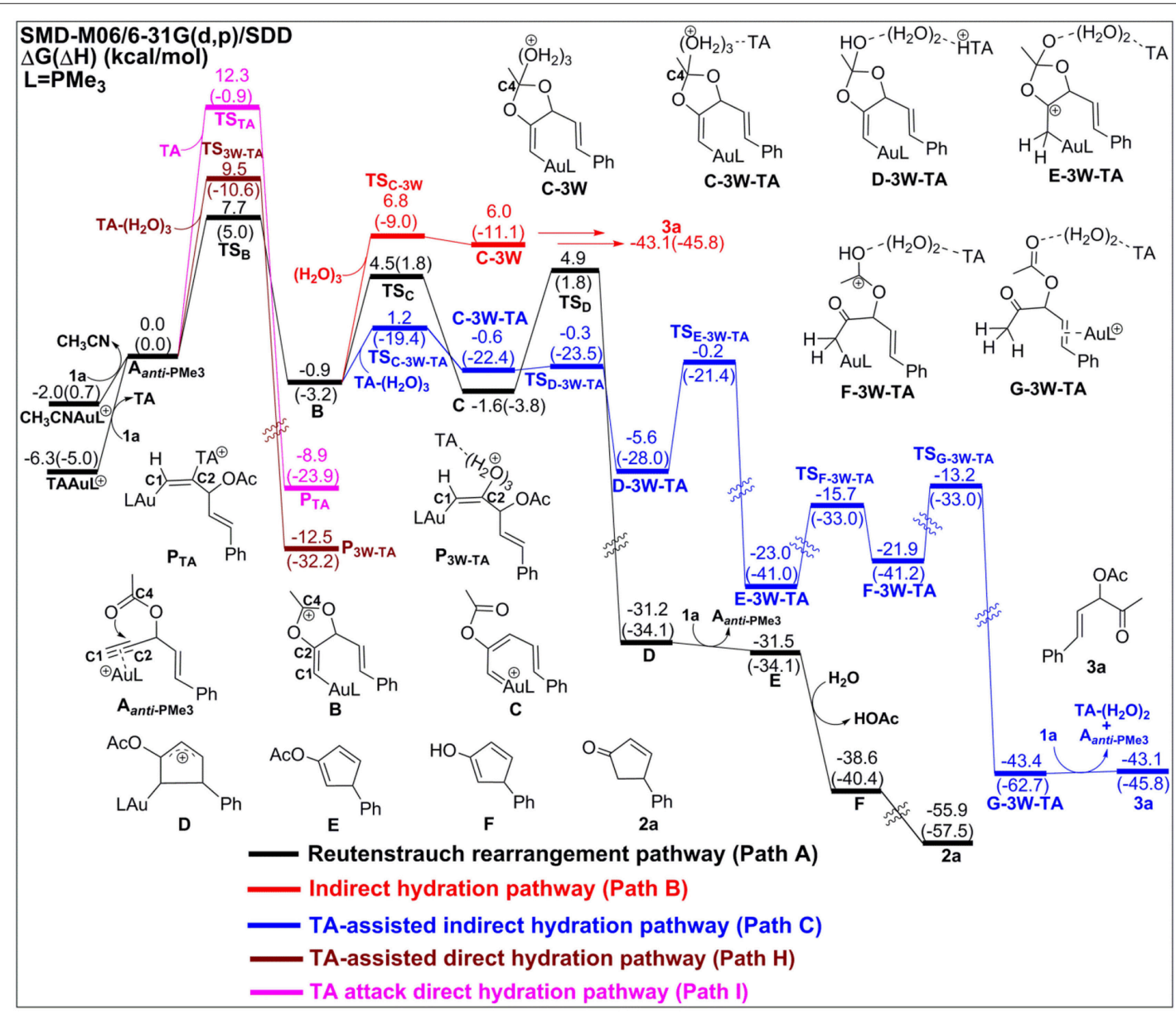

FIGURE 4 | Relative Gibbs free energy and enthalpy (in parenthesis) (kcal/mol) profiles for Au-catalyzed Rautenstrauch rearrangement (black line), indirect hydrations (no-TA-assisted case in red line and TA-assisted case in blue line), TA-assisted direct hydration (purple line), and TA attack direct hydration (pink line) of propargyl ester initiated by $\mathbf{A}_{\text {anti-PMe3 }}$.

been generally found and accepted in protic-solvent-catalyzed organic and biochemical reactions (Fakhraian and Panbeh Riseh, 2005; Kim et al., 2006).

\section{Process 3: Formation of $\alpha$-Acetoxy Ketone}

Similar to the 1,2-acyloxy migration, we found that the C4-O2 in intermediate E-3W-TA is significantly weaker than that of 
normal C-O single bond (1.43 $\mathrm{A})$ and other $\mathrm{C}-\mathrm{O}$ bonds in E3W-TA (1.38 for C4-O1, 1.43 for C3-O1, and $1.31 \AA$ for C2$\mathrm{O} 2$, Figure S5), as demonstrated by its elongated bond length of $1.49 \AA$. Hence, cleavage of the C4-O2 bond can easily take place, with a free energy barrier of $7.3 \mathrm{kcal} / \mathrm{mol}$, leading to an isomerization into the intermediate F-3W-TA. The subsequent protodeauration followed by the release of TA- $\left(\mathrm{H}_{2} \mathrm{O}\right)_{2}$ cluster gives the desired $\alpha$-acetoxy ketone $2 \mathbf{a}$. This process requires an activation energy of $8.7 \mathrm{kcal} / \mathrm{mol}$, accompanying by a free energy release of $21.5 \mathrm{kcal} / \mathrm{mol}$, as displayed in Figure 4 .

It is worth to note that the above mentioned reactions may also have the similar possibility to occur in $\mathbf{A}_{\boldsymbol{s y n} \text {-PMe } 3 \text { as }}$ these two types of complexes ( $\mathbf{A}_{\boldsymbol{a n t i - P M e} 3}$ and $\mathbf{A}_{\boldsymbol{s y n}-\mathrm{PMe} 3}$ ) were found under nearly equilibrium state. From our computational results (Figure $\mathbf{S 6}$ for all pathways initiated by $\mathbf{A}$ syn-PMe3 in the absence/presence of TA), the anti-types of various paths are found to be more favorable.

According to our calculations, we can draw a conclusion that the chemoselectivity of entitled TA-Au catalyzed propargyl ester reactions would rely on the first two steps in each pathway. As shown in Figures 2, 4, the lowest free energy barrier for the first step is associated with the anti-type of 5-exo-dig cyclization in Path A, B, and C. That is, the intramolecular 5-exo-dig cyclization benefit from the nature of nucleophilic attack, is more favorable for the Rautenstrauch rearrangement (Path A) and hydration reactions (Path B and C). Subsequently, the existence of TA further promotes the nucleophilic attack and makes Path $\mathrm{C}$ the most favorable pathway in comparison with the Rautenstrauch rearrangement (Path A) and water-assisted hydration reaction (Path $\mathrm{B}$ ). Therefore, the desired $\alpha$-acetoxy ketone was obtained in the experiment with the assistance of TA. In summary, TA not only stabilizes the Au catalysts, but also alters the chemoselectivity of Au catalyzed propargyl ester reactions, and simultaneously acts as a "relay" to promote the proton transfer.

\section{CONCLUSIONS}

The whole Au-catalyzed propargyl ester reactions have been investigated by a comprehensive DFT study. We considered all possible mechanisms, such as 3,3-rearrangement, 1,2acyloxy migration and various hydration reactions, in the absence/presence of TA. Our computational results not only account for the experimental observations, but also clarify the role of TA. Our findings are summarized as follows.

\section{REFERENCES}

Abu Sohel, S. M., and Liu, R. S. (2009). Carbocyclisation of alkynes with external nucleophiles catalysed by gold, platinum and other electrophilic metals. Chem. Soc. Rev. 38, 2269-2281. doi: 10.1039/b807499m

Andrae, D., Häussermann, U., Dolg, M., Stoll, H., and Preuss, H. (1990). Energy-adjusted ab initio pseudopotentials for the second and third row transition elements. Theor. Chim. Acta. 77, 123-141. doi: 10.1007/BF011 14537

Carpenter, J. E., and Weinhold, F. (1988). Analysis of the geometry of the hydroxymethyl radical by the "different hybrids for different
1) Due to the nature of nucleophilic attack, 5-exo-dig cyclization is the most favorable to start the reactions in comparison to the 6-endo-dig and direct hydration.

2) The Rautenstrauch rearrangement (Path A) is found to be both kinetically and thermodynamically favorable in the absence of TA. Whereas, TA-assisted hydration is the most favorable pathway (Path C) in the presence of TA. These fit well with the experimental observed chemoselectivity of $\mathrm{Au}$-catalyzed propargyl ester reactions.

3) TA does not act as a special "X-factor." It has triple effects on this reaction. First of all, TA can stabilize and prevent rapid decomposition of the $\mathrm{Au}$ catalysts. Secondly, the existence of TA promotes the nucleophilic attack and alters the chemoselectivity of this reaction. Moreover, TA acts as a "relay" to promote the proton transfer.

Our calculation results not only shed light on the role of TA, but also highlight the possible way for the experimental design of more efficient catalysts with desired chemoselectivity.

\section{DATA AVAILABILITY}

The raw data supporting the conclusions of this manuscript will be made available by the authors, without undue reservation, to any qualified researcher.

\section{AUTHOR CONTRIBUTIONS}

This work was completed by cooperation of all authors. AW and XL were responsible for the study of concept and design of the project. QS, PH, and DW searched the intermediates, transition states, analyzed the data, and drew energy profiles. QS, PH, DW, AW, KT, and XL drafted, revised, and checked the manuscript.

\section{FUNDING}

This work was supported by the National Natural Science Foundation of China (21273177, 91545105, and 21773193).

\section{SUPPLEMENTARY MATERIAL}

The Supplementary Material for this article can be found online at: https://www.frontiersin.org/articles/10.3389/fchem. 2019.00609/full\#supplementary-material

spins" natural bond orbital procedure. J. Mol. Struct. 169, 41-62. doi: 10.1016/0166-1280(88)80248-3

Chen, Y., Liu, Y., Petersen, J. L., and Shi, X. (2008). Conformational control in the regioselective synthesis of N-2-substituted-1,2,3-triazoles. Chem. Commun. 3254-3256. doi: 10.1039/b805328f

Chen, Y., Yan, W., Akhmedov, N. G., and Shi, X. (2010). 1,2,3-triazole as a special "X-Factor" in promoting hashmi phenol synthesis. Org. Lett. 12, 344-347. doi: 10.1021/ol902680k

Corma, A., Leyva-Perez, A., and Sabater, M. J. (2011). Gold-catalyzed carbon-heteroatom bond-forming reactions. Chem. Rev. 111, 1657-1712. doi: $10.1021 / \mathrm{cr} 100414 \mathrm{u}$ 
de Frémont, P., Scott, N. M., Stevens, E. D., and Nolan, S. P. (2005). synthesis and structural characterization of N-heterocyclic carbene gold(I) complexes. Organometallics. 24, 2411-2418. doi: 10.1021/om050111c

Diez-Gonzalez, S., Marion, N., and Nolan, S. P. (2009). N-heterocyclic carbenes in late transition metal catalysis. Chem. Rev. 109, 3612-3676. doi: $10.1021 / \mathrm{cr} 900074 \mathrm{~m}$

Diez-Gonzalez, S., and Nolan, S. P. (2008). Copper, silver, and gold complexes in hydrosilylation reactions. Acc. Chem. Res. 41, 349-358. doi: 10.1021/ar7001655

Ding, D., Mou, T., Feng, M., and Jiang, X. (2016). Utility of ligand effect in homogenous gold catalysis: enabling regiodivergent $\pi$-bond-activated cyclization. J. Am. Chem. Soc. 138, 5218-5221. doi: 10.1021/jacs.6b01707

Ditchfield, R., Hehre, W. J., and Pople, J. A. (1971). Self-consistent molecular-orbital methods. IX. An extended gaussian-type basis for molecular-orbital studies of organic molecules. J. Chem. Phys. 54, 724-728. doi: 10.1063/1.1674902

Dorel, R., and Echavarren, A. M. (2015). Gold(I)-catalyzed activation of alkynes for the construction of molecular complexity. Chem. Rev. 115, 9028-9072. doi: $10.1021 / \mathrm{cr} 500691 \mathrm{k}$

Duan, H., Sengupta, S., Petersen, J. L., Akhmedov, N. G., and Shi, X. (2009a). Triazole-Au(I) complexes: a new class of catalysts with improved thermal stability and reactivity for intermolecular alkyne hydroamination. J. Am. Chem. Soc. 131, 12100-12102. doi: 10.1021/ja9041093

Duan, H., Yan, W., Sengupta, S., and Shi, X. (2009b). Highly efficient synthesis of vinyl substituted triazoles by $\mathrm{Au}(\mathrm{I})$ catalyzed alkyne activation. Bioorg. Med. Chem. Lett. 19, 3899-3902. doi: 10.1016/j.bmcl.2009.03.096

Ebule, R. E., Malhotra, D., Hammond, G. B., and Xu, B. (2016). Ligand effects in the gold catalyzed hydration of alkynes. Adv. Synth. Catal. 358, 1478-81. doi: 10.1002/adsc.201501079

Fakhraian, H., and Panbeh Riseh, M. B. (2005). Two-step protic solvent-catalyzed reaction of phenylethylamine with methyl acrylate. Org. Prep. Proced. Int. 37, 579-584. doi: 10.1080/00304940509354990

Faza, O. N., and López, C. S. (2013). Computational study of goldcatalyzed homo- and cross-coupling reactions. J. Org. Chem. 78, 4929-4939. doi: $10.1021 /$ jo4005603

Foster, J. P., and Weinhold, F. (1980). Natural hybrid orbitals. J. Am. Chem. Soc. 102, 7211-7218. doi: 10.1021/ja00544a007

Frisch, M. J., Trucks, G. W., Schlegel, H. B., Scuseria, G. E., Robb, M. A., Cheeseman, J. R., et al. (2013). Gaussian 09, Revision E.01. Wallingford, CT: Gaussian, Inc.

Fürstner, A., and Davies, P. W. (2007). Catalytic carbophilic activation: catalysis by platinum and gold $\pi$ acids. Angew. Chem. Int. Ed. 46, 3410-3449. doi: 10.1002/anie.200604335

Gonzalez, C., and Schlegel, H. B. (1990). Reaction path following in massweighted internal coordinates. J. Phys. Chem. 94, 5523-5527. doi: 10.1021/j1003 $77 \mathrm{a} 021$

Gorin, D. J., Sherry, B. D., and Toste, F. D. (2008). Ligand effects in homogeneous Au catalysis. Chem. Rev. 108, 3351-3378. doi: 10.1021/cr068430g

Gorin, D. J., and Toste, F. D. (2007). Relativistic effects in homogeneous gold catalysis. Nature 446, 395-403. doi: 10.1038/nature05592

Hariharan, P. C., and Pople, J. A. (1973). The influence of polarization functions on molecular orbital hydrogenation energies. Theo. Chim. Acta. 28, 213-222. doi: 10.1007/BF00533485

Hariharan, P. C., and Pople, J. A. (1974). Accuracy of AH n equilibrium geometries by single determinant molecular orbital theory. Mol. Phys. 27, 209-214. doi: 10.1080/00268977400100171

Hashmi, A. S. K. (2003). Homogeneous gold catalysts and alkynes: a successful liaison. Gold Bull. 36, 3-9. doi: 10.1007/BF03214859

Hashmi, A. S. K. (2007). Gold-catalyzed organic reactions. Chem. Rev. 107, 3180-3211. doi: 10.1021/cr000436x

Hashmi, A. S. K. (2010). Homogeneous gold catalysis beyond assumptions and proposal-characterized intermediates. Angew. Chem. Int. Ed. 49, 5232-5241. doi: 10.1002/anie.200907078

Hashmi, A. S. K. (2014). Dual gold catalysis. Acc. Chem. Res. 47, 864-876. doi: 10.1021/ar500015k

Hashmi, A. S. K., and Hutchings, G. J. (2006). Gold catalysis. Angew. Chem. Int. Ed. 45, 7896-7936. doi: 10.1002/anie.200602454

Hehre, W. J., Ditchfield, R., and Pople, J. A. (1972). Self-consistent molecular orbital methods. XII. Further extensions of gaussian-type basis sets for use in molecular orbital studies of organic molecules. J. Chem. Phys. 56, 2257-2261. doi: 10.1063/1.1677527

Hopkinson, M. N., Tlahuext-Aca, A., and Glorius, F. (2016). Merging visible light photoredox and gold catalysis. Acc. Chem. Res. 49, 2261-2272. doi: 10.1021/acs.accounts.6b00351

Hosseyni, S., Su, Y., and Shi, X. (2015). Gold catalyzed synthesis of substituted furan by intermolecular cascade reaction of propargyl alcohol and alkyne. Org. Lett. 17, 6010-6013. doi: 10.1021/acs.orglett.5b02980

Jiménez-Núñez, E., and Echavarren, A. M. (2008). Gold-catalyzed cycloisomerizations of enynes: a mechanistic perspective. Chem. Rev. 108, 3326-3350. doi: 10.1021/cr0684319

Jin, L., Wu, Y., and Zhao, X. (2016). Theoretical insight into the Au(i)catalyzed hydration of halo-substituted propargyl acetate: dynamic waterassisted mechanism. RSC Adv. 6, 89836-89846. doi: 10.1039/C6RA13897G

Kim, D. W., Ahn, D. S., Oh, Y. H., Lee, S., Kil, H. S., Oh, S. J., et al. (2006). A new class of SN2 reactions catalyzed by protic solvents: Facile fluorination for isotopic labeling of diagnostic molecules. J. Am. Chem. Soc. 128, 16394-16397. doi: $10.1021 /$ ja0646895

Kovács, G., Schubert, G., Joó, F., and Pápai, I. (2005). Theoretical mechanistic study of rhodium(I) phosphine-catalyzed H/D exchange processes in aqueous solutions. Organometallics 24, 3059-3065. doi: 10.1021/om0501529

Krause, N., and Winter, C. (2011). Gold-catalyzed nucleophilic cyclization of functionalized allenes: a powerful access to carbo- and heterocycles. Chem. Rev. 111, 1994-2009. doi: 10.1021/cr1004088

Legault, C. Y. (2009). CYLview, 1.0b. Université de Sherbrooke: Sherbrooke, QC, Canada. Available online at: http://www.cylview.org (accessed August 27, 2019).

Liu, Y., Yan, W., Chen, Y., Petersen, J. L., and Shi, X. (2008). Efficient synthesis of N-2-Aryl-1,2,3-triazole fluorophores via post-triazole arylation. Org. Lett. 10, 5389-5392. doi: 10.1021/ol802246q

Marenich, A. V., Cramer, C. J., and Truhlar, D. G. (2009). Universal solvation model based on solute electron density and on a continuum model of the solvent defined by the bulk dielectric constant and atomic surface tensions. J. Phys. Chem. B 113, 6378-6396. doi: 10.1021/jp810292n

Marion, N., Diez-Gonzalez, S., de Fremont, P., Noble, A. R., and Nolan, S. P. (2006). Au(I)-catalyzed tandem [3,3] rearrangement-intramolecular hydroarylation: mild and efficient formation of substituted indenes. Angew. Chem. Int. Ed. Engl. 45, 3647-3650. doi: 10.1002/anie.200600571

Obradors, C., and Echavarren, A. M. (2014a). Gold-catalyzed rearrangements and beyond. Acc. Chem. Res. 47, 902-912. doi: 10.1021/ar400174p

Obradors, C., and Echavarren, A. M. (2014b). Intriguing mechanistic labyrinth in gold(I) catalysis. Chem. Commun. 50, 16-28. doi: 10.1039/C3CC45518A

Ohno, H. (2013). Gold-catalyzed cascade reactions of alkynes for construction of polycyclic compounds. ISR. J. Chem. 53, 869-882. doi: 10.1002/ijch.201300054

Ramón, R. S., Gaillard, S., Slawin, A. M. Z., Porta, A., D’Alfonso, A., Zanoni, G., et al. (2010). Gold-catalyzed meyer-schuster rearrangement: application to the synthesis of prostaglandins. Organometallics 29, 3665-3668. doi: 10.1021/om1005534

Reed, A. E., Curtiss, L. A., and Weinhold, F. (1988). Intermolecular interactions from a natural bond orbital, donor-acceptor viewpoint. Chem. Rev. 88, 899-926. doi: 10.1021/cr00088a005

Rudolph, M., and Hashmi, A. S. K. (2012). Gold catalysis in total synthesis-an update. Chem. Soc. Rev. 41, 2448-2462. doi: 10.1039/C1CS15279C

Sengupta, S., Duan, H., Lu, W., Petersen, J. L., and Shi, X. (2008). One step cascade synthesis of 4,5-disubstituted-1,2,3-(NH)-triazoles. Org. Lett. 10, 1493-1496. doi: $10.1021 / \mathrm{ol} 8002783$

Shapiro, N. D., and Toste, F. D. (2008). Synthesis and structural characterization of isolable phosphine coinage metal $\pi$-complexes. Proc. Natl. Acad. Sci. U.S.A. 105:2779. doi: 10.1073/pnas.0710500105

Shen, W.-B., Sun, Q., Li, L., Liu, X., Zhou, B., Yan, J.-Z., et al. (2017a). Divergent synthesis of $\mathrm{N}$-heterocycles via controllable cyclization of azido-diynes catalyzed by copper and gold. Nat. Commun. 8:1748. doi: 10.1038/s41467-017-01853-1

Shen, W.-B., Xiao, X.-Y., Sun, Q., Zhou, B., Zhu, X.-Q., Yan, J.-Z., et al. (2017b). Highly site selective formal [5+2] and [4+2] annulations of isoxazoles with heterosubstituted alkynes by platinum catalysis: rapid access to functionalized 1,3-oxazepines and 2,5-dihydropyridines. Angew. Chem. Int. Ed. 56, 605-609. doi: 10.1002/anie.201610042 
Shi, F.-Q., Li, X., Xia, Y., Zhang, L., and Yu, Z.-X. (2007). DFT study of the mechanisms of in water $\mathrm{Au}(\mathrm{I})$-catalyzed tandem [3,3]-rearrangement/nazarov reaction/[1,2]-hydrogen shift of enynyl acetates: a proton-transport catalysis strategy in the water-catalyzed [1,2]-hydrogen shift. J. Am. Chem. Soc. 129, 15503-15512. doi: 10.1021/ja071070+

Shi, X., Gorin, D. J., and Toste, F. D. (2005). Synthesis of 2-cyclopentenones by gold(I)-catalyzed rautenstrauch rearrangement. J. Am. Chem. Soc. 127, 5802-5803. doi: $10.1021 / \mathrm{ja} 051689 \mathrm{~g}$

Shu, C., Wang, Y.-H., Zhou, B., Li, X.-L., Ping, Y.-F., Lu, X., et al. (2015). Generation of $\alpha$-imino gold carbenes through gold-catalyzed intermolecular reaction of azides with Ynamides. J. Am. Chem. Soc. 137, 9567-9570. doi: $10.1021 /$ jacs.5b06015

Wang, D., Cai, R., Sharma, S., Jirak, J., Thummanapelli, S. K., Akhmedov, N. G., et al. (2012b). "Silver Effect" in gold(I) catalysis: an overlooked important factor. J. Am. Chem. Soc. 134, 9012-9019. doi: 10.1021/ja303862z

Wang, D., Gautam, L. N. S., Bollinger, C., Harris, A., Li, M., and Shi, X. (2011a). 1,2,3-triazole bound $\mathrm{Au}(\mathrm{I})$ (TA-Au) as chemoselective catalysts in promoting asymmetric synthesis of substituted allenes. Org. Lett. 13, 2618-2621. doi: 10.1021/ol200714h

Wang, D., Ye, X., and Shi, X. (2010). Efficient synthesis of E- $\alpha$-haloenones through chemoselective alkyne activation over allene with triazole-Au catalysts. Org. Lett. 12, 2088-2091. doi: 10.1021/ol100576m

Wang, D., Zhang, Y., Cai, R., and Shi, X. (2011b). Triazole-Au(I) complex as chemoselective catalyst in promoting propargyl ester rearrangements. Beilstein J. Org. Chem. 7, 1014-1020. doi: 10.3762/bjoc.7.115

Wang, D., Zhang, Y., Harris, A., Gautam, L. N. S., Chen, Y., and Shi, X. (2011c). Triazole-gold-promoted, effective synthesis of enones from propargylic esters and alcohols: a catalyst offering chemoselectivity, acidity and ligand economy. Adv. Synth. Catal. 353, 2584-2588. doi: 10.1002/adsc.201100314
Wang, Q., Aparaj, S., Akhmedov, N. G., Petersen, J. L., and Shi, X. (2012c). Ambient schmittel cyclization promoted by chemoselective triazole-gold catalyst. Org. Lett. 14, 1334-1337. doi: 10.1021/ol300227a

Wang, W., Hammond, G. B., and $\mathrm{Xu}$, B. (2012a). Ligand effects and ligand design in homogeneous gold(I) catalysis. J. Am. Chem. Soc. 134, 5697-5705. doi: $10.1021 /$ ja3011397

Yan, W., Wang, Q., Chen, Y., Petersen, J. L., and Shi, X. (2010). Iron-catalyzed $\mathrm{C}-\mathrm{O}$ bond activation for the synthesis of propargyl-1,2,3-triazoles and 1,1-bistriazoles. Org. Lett. 12, 3308-3311. doi: 10.1021/ol101082v

Zhang, L. (2014). A non-diazo approach to $\alpha$-oxo gold carbenes via goldcatalyzed alkyne oxidation. Acc. Chem. Res. 47, 877-888. doi: 10.1021/ar40 $0181 x$

Zhao, Y., and Truhlar, D. G. (2008). The M06 suite of density functionals for main group thermochemistry, thermochemical kinetics, noncovalent interactions, excited states, and transition elements: two new functionals and systematic testing of four M06-class functionals and 12 other functionals. Theor. Chem. Acc. 120, 215-241. doi: 10.1007/s00214-007-0310-x

Conflict of Interest Statement: The authors declare that the research was conducted in the absence of any commercial or financial relationships that could be construed as a potential conflict of interest.

Copyright $\odot 2019$ Sun, Hong, Wei, Wu, Tan and Lu. This is an open-access article distributed under the terms of the Creative Commons Attribution License (CC BY). The use, distribution or reproduction in other forums is permitted, provided the original author(s) and the copyright owner(s) are credited and that the original publication in this journal is cited, in accordance with accepted academic practice. No use, distribution or reproduction is permitted which does not comply with these terms. 